\title{
The environmental consequences of implementation of a council directive on landfill of waste in Lithuania
}

\author{
G. Denafas \\ Department of Environmental Engineering, \\ Kaunas University of Technology, Lithuania
}

\begin{abstract}
While establishing feasibilities for municipal waste management system development in Lithuania, the generation of municipal waste management fractions have been forecast, using a LCA-IWM prognostic tool. Separate collection and treatment of $22 \%$ of biodegradable waste from the total biodegradable waste amount has been proposed, based on this forecast. The next steps of the Lithuanian Municipal Waste Management System development may be the arrangement of some environmentally friendly mixed municipal waste incineration plants. Such scenarios fully satisfy the requirements of the Council Directive on Landfill of Waste and Lithuanian State Strategic Waste Management Plan concerning the reduction of landfilled biodegradable waste.

The assessment of these scenarios of environmental consequences shows that in the Lithuanian municipal waste management system the emissions of greenhouse gas, human toxicity and photo-oxidants formation would be reduced significantly after the decrease in biodegradable waste landfilling. However, due to biogas and mixed municipal waste incineration the acidification and eutrophication would be increased visibly.
\end{abstract}

Keywords: municipal waste, landfilling, biodegradable waste, incineration, greenhouse gas, human toxicity, acidification, eutrophication.

\section{Introduction}

The goal of Council Directive 1999/31/EB on landfill of waste is: to schedule the means, order and guidelines which would help to prevent or highly reduce the negative environmental impact, especially the pollution of surface water, 
groundwater, soil and air, the global environment, including the greenhouse effect and the hazard to humans emerging from landfills during waste disposal and periods of landfill exploitation by applying the strong demands for waste and landfills. The minimising strategy may secure the reduction of biodegradable waste landfilling by composting and biogas, and production, material and energy recycling may achieve $75 \%$ from the total biodegradable waste mass generated in $1995 \mathrm{~m}$ [3].

Lithuania, as a new EU member-country, implements the Council Directive on Landfill of Waste step-by step. The State Strategic Waste Management Plan regulates that in 2010 the amount of landfilled biodegradable waste may not exceed $75 \%$ of that in 2000 ; the landfilled amount of biodegradable waste in $2013-50 \%$, and in $2020-35 \%$. [5]

Lithuanian waste management regions practically match Lithuanian counties. Thus, Lithuania is divided into 10 waste management regions: Vilnius, Kaunas, Alytus, Marijampole, Utena, Panevezys, Siauliai, Telsiai, Taurage and Klaipeda (Figure 1). Modern regional landfills with leachate treatment and landfill gas collection systems are arranged for every region, according to EU requirements [6].

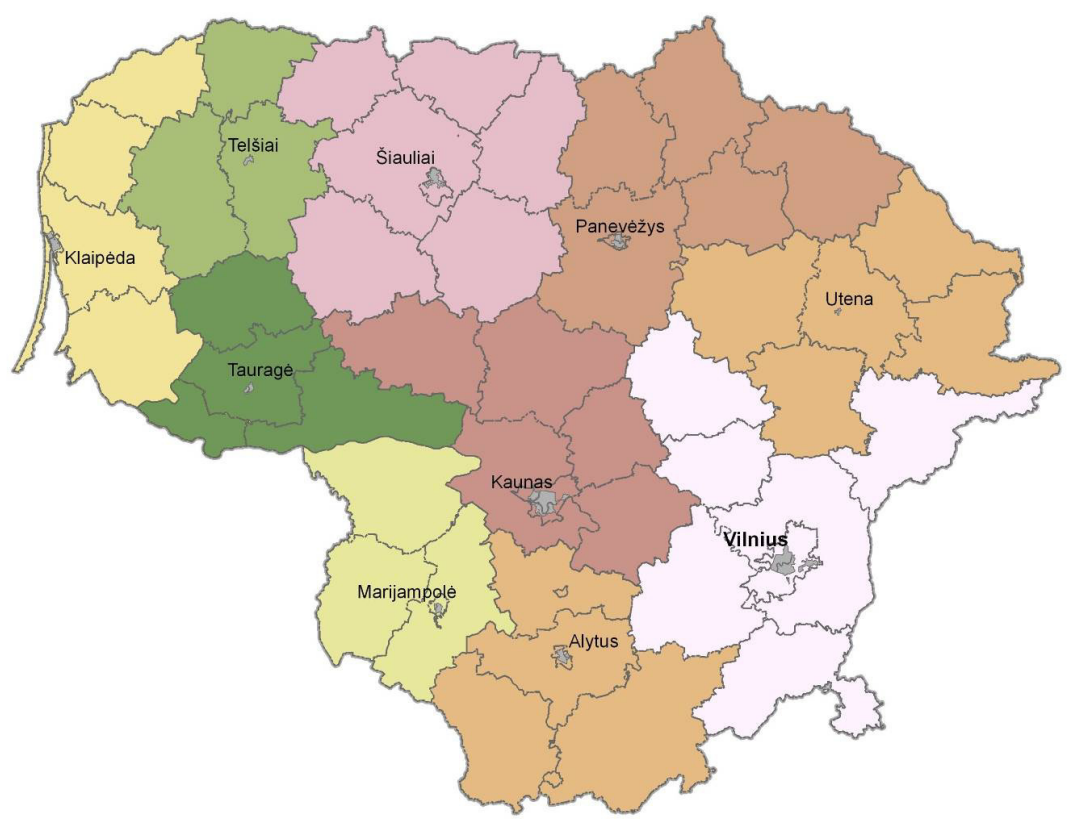

Figure 1: Waste management regions in Lithuania. 


\section{Waste generation and management - forecasts and scenarios}

The forecasts of municipal solid waste generation and fractions collection for Lithuania, according to the GDP average growing scenario till 2020, had been prepared by the LCA-IWM prognostic tool [1] (Figure 2) and are presented in Figure 3.

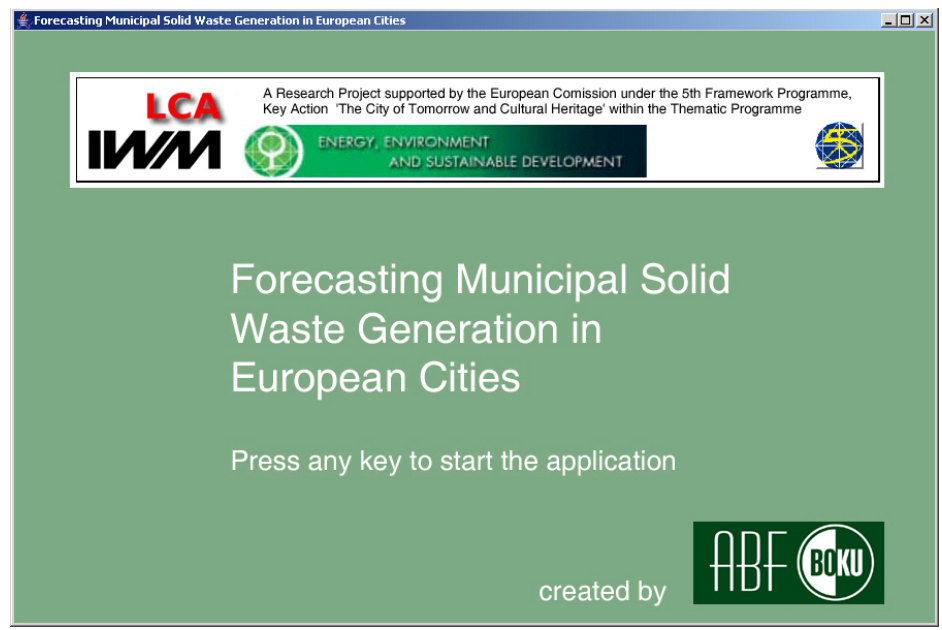

Figure 2: Initial screen of the LCA-IWM Waste Prognostic Tool [1].

Municipal waste fractions collection forecasts

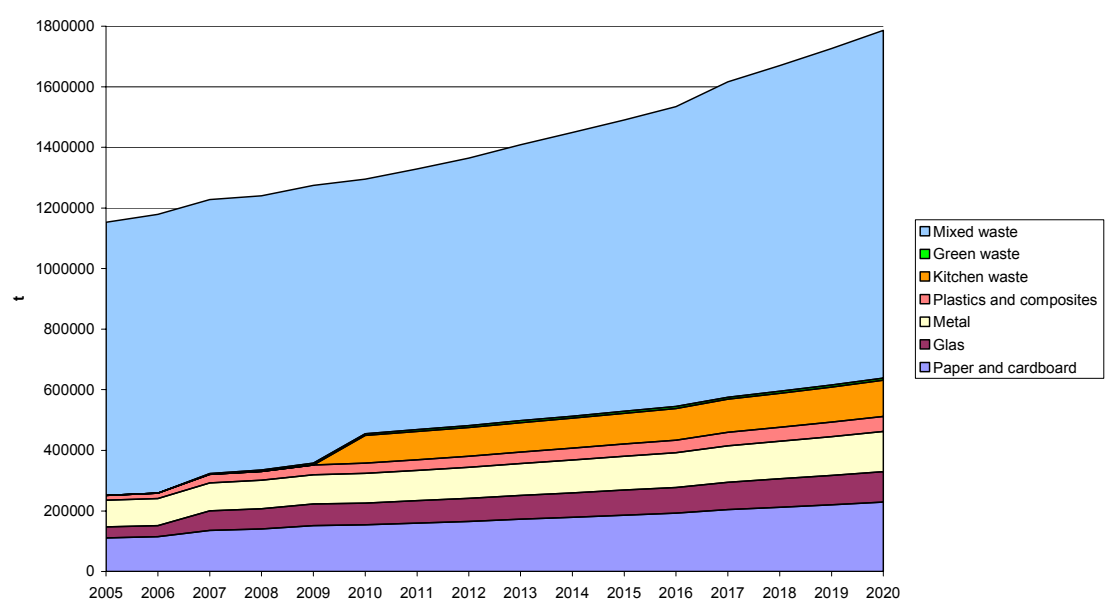

Figure 3: Municipal waste collection forecast for Lithuania in the period of $2005-2020$. 
If the secondary raw material collection system will is implemented from 2007, paper, cardboard, glass and plastics collection efficiency will increase. From 2010, after the implementation of the above mentioned system, the collection of biodegradable waste, predominantly consisting of kitchen waste, will be increased significantly too, and the part consisting of garden waste would remain mainly like that in 2006 .

During the entire investigated period the mixed municipal waste will be predominant between all collected fractions because the possible achievement of higher collection rate is undetermined.

\subsection{Forecasted composition of mixed municipal waste}

Considering the planned separate collection of waste fractions, the composition of mixed municipal waste may vary according to the scheme, presented in Figure 4. The higher content of biodegradable fractions especially causes the higher environmental impact by implementing various waste treatment and disposal technologies [3].

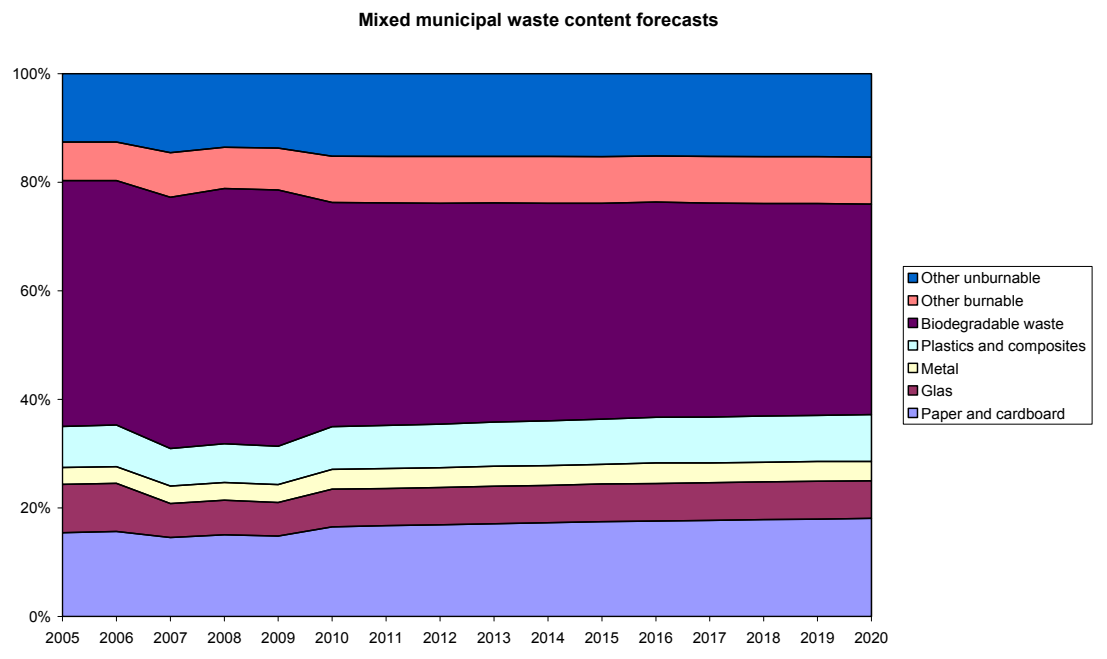

Figure 4: Forecast of mixed municipal waste composition for Lithuania in the period of $2005-2020$.

\subsection{Proposed waste management system development scenarios}

During the Lithuanian municipal waste management system subsequent development feasibility studies, possible alternative scenarios for waste management regions had been formulated:

- Scenario 1. The separate collection of biodegradable waste and its anaerobic digestion with biogas production would be started from 2010, 
and the remaining mixed municipal waste without separately collected biodegradable waste would be landfilled in the regional landfills;

- Scenario 2. The separate collection of biodegradable waste and its anaerobic digestion with biogas production would be started from 2010, the incineration of mixed municipal waste for Vilnius, Utena, Kaunas, Alytus and Marijampole regions would be started from 2013, for Klaipeda, Telsiai and Taurage regions - from 2020;

- Scenario 3. The separate collection of biodegradable waste and its anaerobic digestion with biogas production would be started from 2010, the incineration of mixed municipal waste for all regions except Siauliai and Panevezys regions would be started from 2013;

- Scenario 4. The separate collection of biodegradable waste and its anaerobic digestion with biogas production would be started from 2010, the incineration of mixed municipal waste for all regions would be started from 2013;

Scenarios 2, 3, and 4 would completely satisfy the demands of Lithuanian State Strategy Waste Management Plan. Scenario 1 would satisfy this plan only for 2010.

\section{Possible environmental consequences}

The environmental consequences of the proposed municipal waste management scenarios have been assessed. Such indicators as greenhouse gas emissions, human toxicity, photo-oxidant formation, acidity and eutrophication have been evaluated. The units for the greenhouse gas emissions indicator are given as $\mathrm{CO}_{2}$ equivalents, i.e. for human toxicity $-1,4$ dichlorbenzene equivalents, for acidity $-\mathrm{SO}_{2}$ equivalents, for eutrophication $-\mathrm{PO}_{4}{ }^{3-}$ equivalents. The assessment has been performed using the algorithmic system of LCA-IWM assessment model $[1,2]$ (Figure 5). It is specially established for environmental impact assessment in the various municipal waste management processes.

\subsection{Greenhouse gas emissions}

The changes of greenhouse gas emissions from Lithuanian municipal waste management system in the cases of all the above mentioned waste management scenarios are presented in Figure 6. Due to the started utilisation of landfill gases (with $60 \%$ methane - one of the main greenhouse gases) their emissions by 2010 may decrease very significantly. At 2013, when the incineration of mixed municipal waste would start, the greenhouse gas emissions would be decreased. Additionally, these emissions will be diminished due to a corresponding decrease of landfilled biodegradable fractions of mixed municipal waste, (it should be noted that landfill gas utilisation doesn't reduce the methane emissions completely). The influence of separately collected biodegradable waste treatment would be insignificant. 
468 Ecosystems and Sustainable Development VI

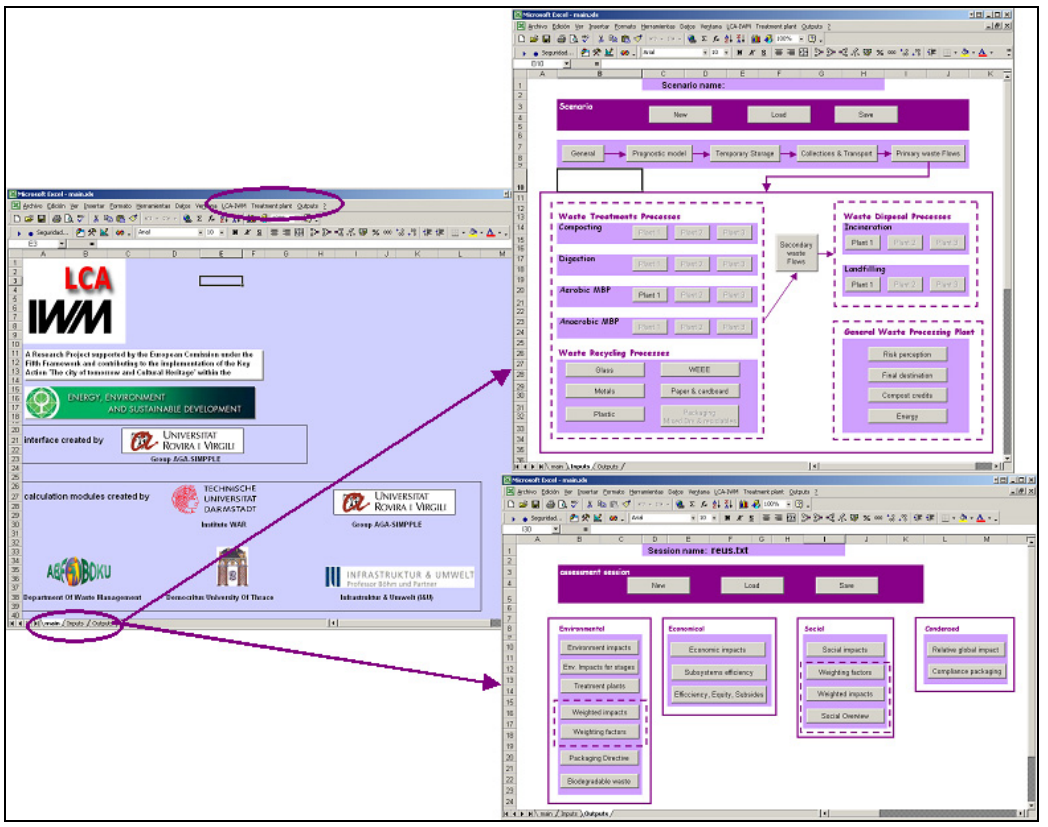

Figure 5: $\quad$ LCA-IWM Assessment Tool initial screen [1,2].

Greenhouse gas emissions forecasts in the Lithuanian MSW system

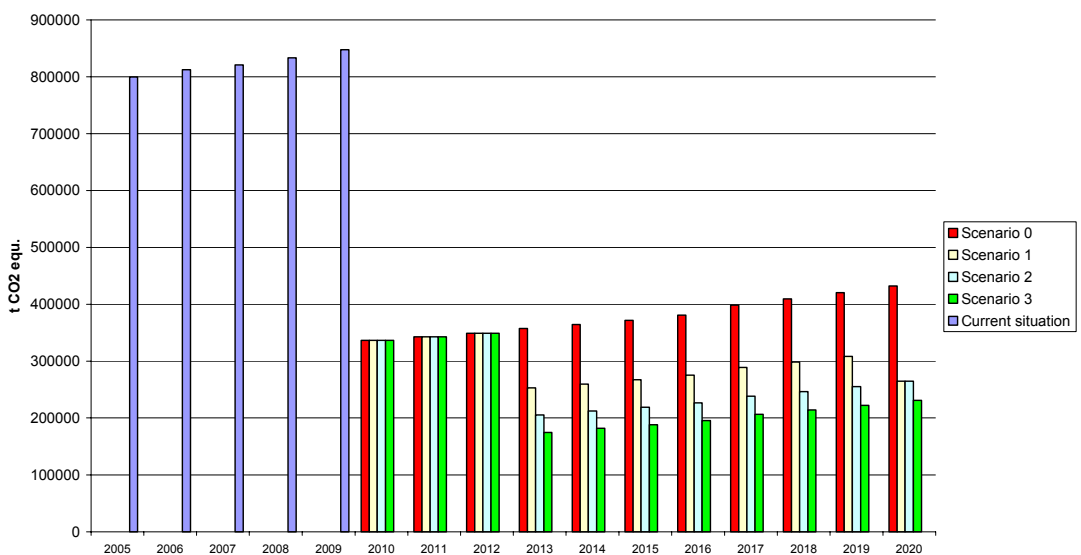

Figure 6: The tendencies of greenhouse gas emissions caused by Lithuanian municipal waste management system during current and forecasted period till 2020 . 


\subsection{Human toxicity}

The possible changes of human toxicity causing emissions in the Lithuanian municipal waste management system are presented in Figure 7.

Human toxicity may increase significantly in 2010 due to the start of incineration of landfill gases. Such assessment doesn't show the real risk for the environment - the calculation of pollutant's dispersions disproves it.

Human toxicity, after 2013 started incineration of mixed municipal waste, would be decreased both due to the reduction of landfill gas emissions and reduction of leachate formation. It should be noted that the whole leachate amount could not be collected and treated. After the comparison of different scenarios we see that where the more mixed municipal waste incineration would be implemented the human toxicity would be reduced. The emissions from incineration plants would not impact on human toxicity due to the exhaust gas treatment devices.

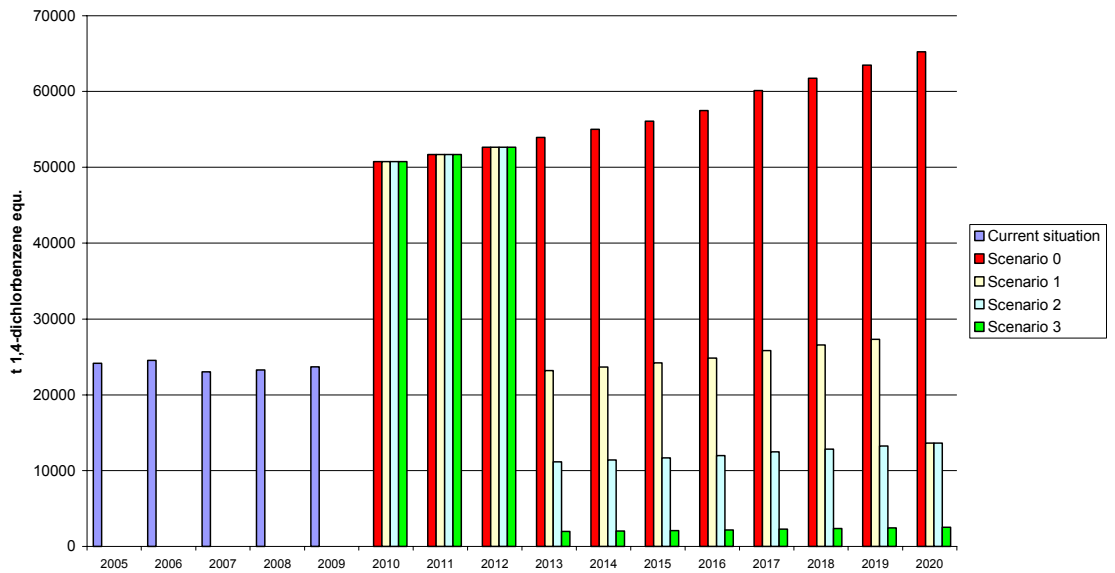

Figure 7: The tendencies of changes of human toxicity indicator caused by Lithuanian municipal waste management system during current and forecasted periods till 2020 .

\subsection{Environment acidification}

Figure 8 shows the possible changes of environmental acidification caused by Lithuanian municipal waste management system in the case of all the mentioned scenarios. These changes are presented only from 2010 when incineration of landfill gas and biogas from anaerobic biodegradable waste treatment starts. During the incineration acidic pollutants, mostly nitrogen oxides, would be 
emitted. From 2013, after the start of mixed municipal waste incineration, the environmental acidity would increase additionally due to the increased emissions of the same nitrogen oxides.

So, not until 2010 would the Lithuanian municipal waste management system have a direct influence to environmental acidification.

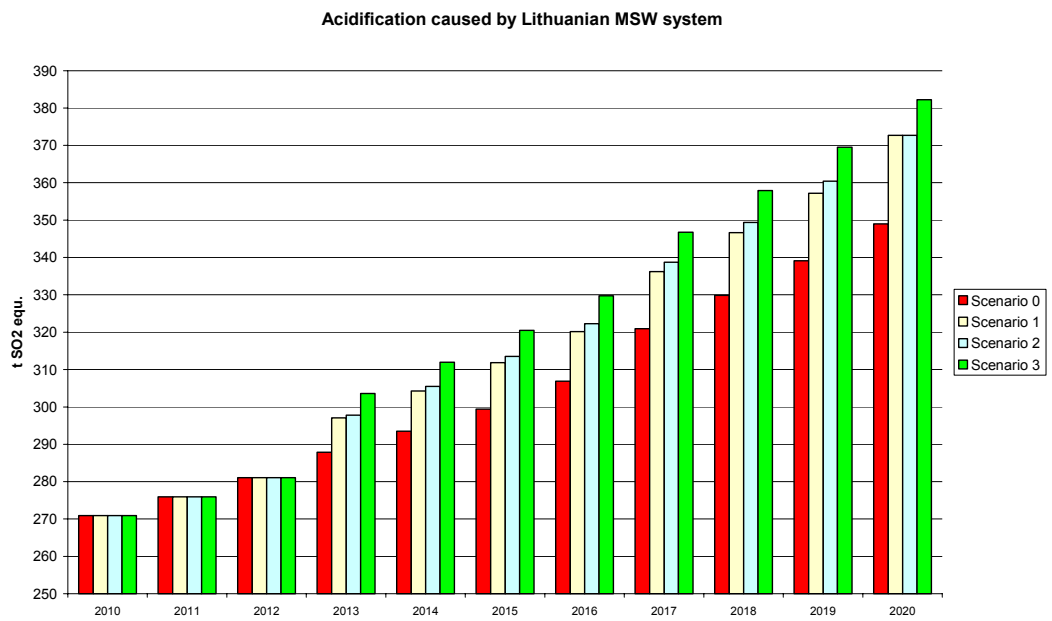

Figure 8: The tendencies of changes of acidification caused by Lithuanian municipal waste management system during the forecasted period till 2020.

\subsection{Eutrophication}

Figure 9 shows the possible changes of eutrophication caused by Lithuanian municipal waste management system for all the mentioned scenarios.

If the mixed municipal waste disposal starts from 2007 in the regional landfills with modern systems of leachate collection and treatment, the eutrophication level caused by Lithuanian municipal waste management system would decrease significantly. However from 2010 and from 2013, due to the increase of the above mentioned nitrogen oxide emissions, the corresponding increase of eutrophication would be observed.

\section{Summary and conclusions}

Municipal waste generation forecasts, obtained by LCA-IWM forecasting model show, that in the Lithuanian waste management system mixed municipal waste with significant bio-waste content will be dominating until 2020, irrespective of increased separate collection of secondary raw-materials and biodegradable fraction. 
Eutrophication caused by Lithuanian MSW system

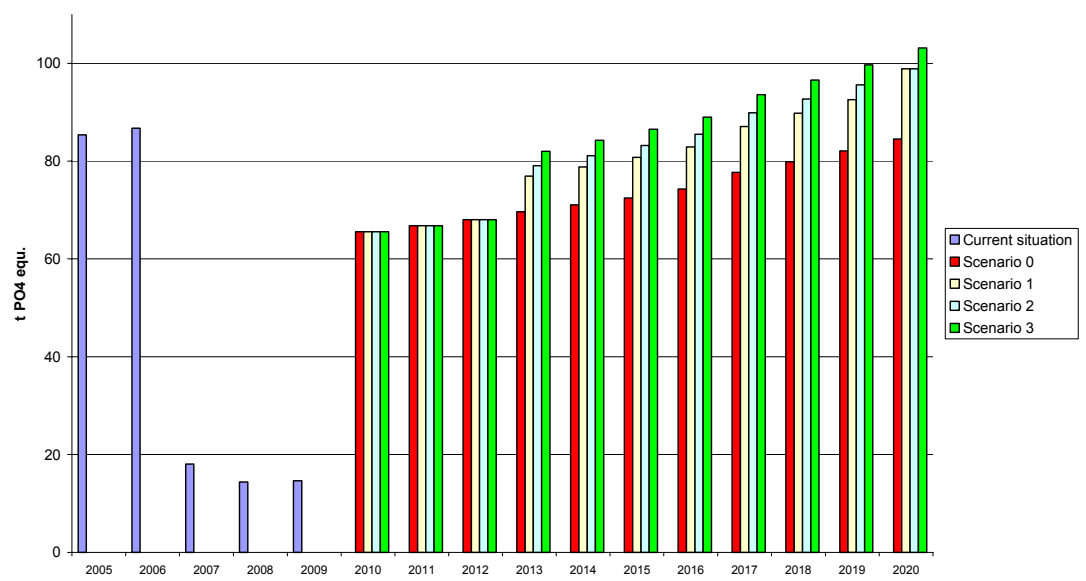

Figure 9: The tendencies of changes of eutrophication caused by Lithuanian municipal waste management system during the forecasted period till 2020.

Regarding the requirements of the Council Directive on Landfill of Waste, Lithuanian State Strategic Waste Management Plan and 10 Lithuanian waste management regions with modern regional landfills, four different municipal waste management scenarios were formulated and corresponding environmental impact assessment using the LCA-IWM assessment tool had been performed.

The assessment results show that:

- landfill gas recovery and energetically useful incineration system would reduce the greenhouse gas emissions 2.5 times, however the human toxicity due to this incineration would increase twofold;

- $\quad$ incineration of mixed municipal waste (with appropriate gas cleaning technologies) would help to avoid the major part of greenhouse gas emissions and human toxicity formed from the same landfilled waste amount;

- $\quad$ the implementation of new waste treatment and disposal technologies like landfilling with landfill gas use, anaerobic digestion of bio-waste with biogas incineration and mixed waste incineration in the Lithuanian waste management system would cause the growth of environmental acidification, mostly caused by emitted nitrogen oxides;

- $\quad$ though an eutrophication would be reduced 5 times by using modern leachate treatment facilities in the regional landfills, however the incineration of landfill gas and mixed solid waste would increase it 4-5 times due to the above mentioned nitrogen oxides emissions; 
- in comparison with common Lithuanian environmental impact dimensions, increased before mentioned negative environmental impact would not achieve $10 \%$, so the implementation of both landfill gas and waste incineration may not be rejected.

\section{Acknowledgements}

The performed research was partially funded by Cohesion foundation and Lithuanian government.

\section{References}

[1] den Boer, E., den Boer, J. \& Jager, J., Waste management planning and optimisation. Handbook for municipal waste prognosis and sustainability assessment of waste management systems, ibidem-Verlag: Stuttgart, pp. 189-274, 2005.

[2] den Boer, E., den Boer, J. \& Jager, J., The Use of the LCA-IWM Tool to Assess the Sustainability of Waste Minimisation. Waste matters. Integrating views. Proceedings of the $2^{\text {nd }}$ BOKU Waste Conference, ed. P. Lechner, Facultas Verlags- und Buchhandels AG, Vienna, p.p. 293-302, 2007.

[3] Deliverable Report on D2.1: Draft Waste Generation Prognostic Model (Work package 2). The Use of Life Cycle Assesment Tools for the Development of Inrtegrated Waste Management Strategies for Cities and Regions with Rapid Growing Economies. LCA-IWM. - Vienna, 30.11.2003

[4] Council Directive 1999/31/EC of 26 April 1999 on the landfill of waste

[5] Resolution of the Lithuanian Republic Government No. 519 of 12 April 2002 "Concerning the Approval of the National Strategic Waste Management Plan“

[6] Vilnius County Regional Waste Management Plan 2006-2016. Environmental Projects Management Agency, Ministry of Environment, Republic of Lithuania, 2006 